DOI 10.37882/2223-2982.2020.09.23

\title{
ОСОБЕННОСТИ ФУНКЦИОНИРОВАНИЯ ЗАИМСТВОВАННОЙ ЛЕКСИКИ В СОВРЕМЕННОМ ФРАНЦУЗСКОМ ЯЗЫКЕ
}

\section{FEATURES OF THE FUNCTIONING OF BORROWED VOCABULARY IN MODERN FRENCH}

L. Nizhina

Summary: The article describes the main trends of assimilation of borrowed vocabulary in modern French. The research is based on the analysis of borrowings and neologisms formed from them, recorded in the explanatory dictionaries of 2017-2020. On the basis of extralinguistic factors and intra-linguistic laws of language functioning, the mechanisms of external and internal ways of adding lexical content, their productivity and thematic areas are analyzed.

Keywords: French language, modern trends in language development, assimilation of borrowings by the recipient language, frequency of parts of speech, thematic areas of new vocabulary, methods of word formation.
Нежина Лариса Александровна

К.филол.н., дочент, Военный университет Министерства обороны Российской Федерации

lar.ren@mail.ru

Аннотация: Статья посвящена описанию основных тенденций ассимиляции заимствованной лексики в современном французском языке. В основе исследования лежит анализ заимствований и образованных от них неологизмов, зафиксированных в толковых словарях 2017-2020 годов. На основе экстралингвистических факторов и внутриязыковых законов функционирования языка анализируются механизмы внешних и внутренних способов пополнения лексического состава, их продуктивность и тематические сферы.

Ключевые слова: французский язык, современные тенденции развития языка, ассимиляция заимствований языком-реципиентом, частотность частей речи, тематические сферы новой лексики, способы словообразования.
Я зык - это сложная система, которая находится в постоянном развитии и подвергается различным изменениям. Однако конец XX и начало XXI веков стали периодом стремительного развития технологий, которое повлекло за собой интенсификацию культурных, экономических и, что не менее важно, социальных и языковых контактов между людьми.

Данные тенденции находят свое отражение в словарном составе любого языка. Современная лингвистика традиционно разделяет способы пополнения национального словаря на внутренние и внешние. Другими словами, пополнение происходит либо за счет внутренних ресурсов языка, либо за счёт заимствований. Материалом для исследования послужили современные французские лексические единицы, отобранные методом простой случайной выборки из словарей новых слов «Dictionnaire des mots nouveaux» Робера за 20172020 гг., а также сопроводительные статьи к ним в количестве 178 единиц.

Отечественные и зарубежные исследователи выделяют экстралингвистические (психологические, эстетические, общественные) и лингвистические (языковедческие) причины проникновения иностранных элементов в принимающие языки. Таким образом, потребность в номинации новых вещей или жизненных явлений, дань моде в употреблении иностранных слов и выражений наряду с потребностью искоренить полисемию и омонимию или унифицировать понятия в узкоспециализи- рованной сфере становятся причинами заимствований.

Современный мир развивается в условиях всемирной глобализации, что послужило основной причиной роста лингвистических контактов между представителями различных стран. В результате появилась проблема заимствования иностранных слов и их адаптации в принимающем языке, которая на протяжении длительного периода постоянно находится в центре внимания исследователей.

В современном французском языке на данном этапе культурно-исторического развития многие заимствования становятся актуализированными, высокочастотными в узусе и их освоение является необходимым условием обеспечения эффективной коммуникации.

Французский язык на протяжении всей своей истории существования заимствовал из различных языков (в том числе живых и мертвых) лексику, за счет которой происходило пополнение или обогащение словарного состава.

Слова, заимствованные из другого языка, не сразу входят в лексическую систему языка-реципиента. Должно пройти определённое время, чтобы осуществился процесс приспособления, так называемая акклиматизация или ассимиляция.

Чаще всего заимствованное слово приспосаблива- 
ется к системе языка-реципиента, выражаясь в новой форме и / или содержании. По мнению отечественных исследователей, «заимствование представляет собой активный процесс, потому что заимствующий язык не пассивно воспринимает чужое слово, постепенно переделывая и подстраивая его в сеть своих внутренних системных отношений» [2, с. 211].

В первую очередь заимствования подвергаются фонетической ассимиляции. И хотя в фактическом материале зафиксированы случаи, в которых французскому языку не потребовалось прибегать к фонетической адаптации, например: vlog ['vlog] (сущ., м. р.) от англ. vlog ['vlog] - периодически обновляемая авторская лента видеосообщений и размышлений на разные темы, каждое из которых может быть прокомментировано читателями (веблог), такое совпадение произносительных тенденций скорее исключение, так как в 93 \% от общего количества проанализированных примеров звуковому образу иноязычного слова приходится приспосабливаться под правила фонетической системы французского языка: ударение всегда переносится на последний слог, труднопроизносимые фонемы иностранных слов устраняются и заменяются привычными для носителей языка фонемами, буквосочетания начинают читаться по правилам чтения языка-реципиента. Нижеследующий пример наглядно иллюстрирует все перечисленные типы изменений: dystopie [disto'pi] (сущ., ж. р.) от англ. dystopia [dIs'təupjə] -литературный жанр, описывающий общество / место, где все плохо (антиутопия).

Более того из примера видно, что фонетическая ассимиляция может сопровождаться и графической адаптацией слова (31,5\%), а именно заменой окончания английского существительного на привычную для французской морфологической системы немую букву «е».

При морфологической ассимиляции в современном французском языке все заимствованные нарицательные существительные приобретают артикль, а слова языкадонора, не имеющие категории рода, распределяются по родам и чаще всего, в 67 \% от общего количества примеров, они приобретают мужской род. Примеров, когда в языке доноре у существительного есть род, но при ассимиляции французским языком он изменяется, при прямом способе заимствования зафиксировано не было.

Однако при опосредованном заимствовании такой вариант возможен, например, слово «katal» (катал единица измерения активности катализатора в Международной системе единиц) пришло во французский язык из древнегреческого. В языке-доноре данное слово являлось существительным женского рода, но так как процесс заимствования проходил опосредованно через английский язык, в котором категория рода у подобного типа существительных отсутствует, то во французском языке, подчиняясь закону частотности, заимствование приобрело мужской род.

Следует отметить тот факт, что в случае заимствования глаголов, данная часть речи в 100 \% подвергается морфологической ассимиляции, а именно приобретает форму, свойственную французским глаголам 1 группы, например:

- coder от англ. глагола to code - программировать;

- texter от англ. глагола to text - общаться путем кратких текстовых сообщений (смс).

Что касается лексической ассимиляции, то в 72,5\% от общего количества проанализированных примеров она отсутствует, то есть значения непосредственно заимствований и их иноязычных прототипов остаются идентичными. Возможно, данный факт объясняется тем, что заимствуются в большинстве своем конкретные или вещественные имена существительные, не имеющие дополнительных или переносных значений, в то время как лексическая ассимиляция заимствованной лексики может осуществляться только при многозначности заимствуемого слова. В таком случае ассимилируется, как правило, одно значение заимствованного слова, т. е. полисем становится моносемом [1, с. 75]. Например, для английского существительного «spoiler» словарь приводит следующие варианты значений:

- грабитель, мародёр,

- то или тот, кто портит что-либо,

- неожиданный победитель,

- помеха, третий лишний (третий кандидат на выборах, портящий шансы наиболее вероятного победителя),

- спойлер (сообщение на форуме, разглашающее информацию, которая должна была стать сюрпризом: развязку детектива, финал кинофильма, исход спортивного матча и т. п.).

Из всех перечисленных значений данное английское существительное, заимствованное французским языком, сохранило только последнее. И такого рода семантическая ассимиляция (26 \%) вполне объясняется тем фактом, что все остальные значения французский язык уже давно вполне способен передать собственными ресурсами.

При семантической ассимиляции также возможен и обратный вышеописанному процесс, то есть когда заимствованное слово не сужает, а наоборот приобретает новый нюанс значения, отличный от его значения в языке-доноре. Но такие случаи крайне редки (1,5%), например: английское существительное biopic (м. р.) помимо присущего ему исходного значения «фильм-биография, биографический фильм» во французском языке расширяет свое значение путем метафорического переноса 
для обозначения и биографических романов.

В случае удачной ассимиляции заимствованная лексема входит в систему языка-реципиента и начинает активно функционировать независимо от жизни его прототипа в языке-источнике. В дальнейшем заимствованное слово также может подергаться новым морфологическим трансформациям, обрастая производными словами или дериватами. Однако учитывая языковую политику Франции данный процесс не всегда однозначен. В борьбе за чистоту языка принимают участие не только представители государственных структур и различных организаций, но также и представители французского народа, которые заинтересованы в сохранении собственной культуры и языка. Заимствованным словам стараются подобрать французские эквиваленты или создать с помощью внутренних ресурсов языка неологизмы, описывающие данный сегмент действительности. Так, например, транслитерированные с английского языка существительные:

- coworking (сущ., м. р.) - в широком смысле - подход к организации труда людей с разной занятостью в общем пространстве; в узком -коллективный офис (коворкинг, сотрудничество);

- like (сущ., м. р.) - популярный в Интернете способ показать свое одобрение какого-либо материала или информации (лайк);

- и акрооним lol - интернет-мем, означающий «громко смеяться», уже сосуществует с французскими вариантами «cotravail», «j'aime», «mdr» - аббревиатура от «mort de rire». Однако процесс замены заимствований собственно французскими словами происходит медленно, о чем говорит низкая продуктивность описанных выше тенденций - 10 \% от общего количества примеров.

Гораздо чаще сами заимствования начинают образовывать дериваты по моделям французского словообразования - 45 \% от общего количества примеров. Тематическая сфера заимствований активно образующих дериваты отличается от общей тематики заимствований тем, что здесь полностью отсутствует сфера гастрономии. Абсолютное большинство дериватов образуются в тематической сфере, описывающей Интернет и информационные технологии (56\%).

Что касается частей речи, которые образуются от заимствований, то чаще всего от заимствованных слов французский язык образует существительные (54 \%), например:

- jobiste - студент, подрабатывающий на каникулах;

- googlage - поиск информации с помощью поисковой системы Гугл;

- youtubeur - пользователь крупнейшего видео-сайта Ютуб;

- ubérisation - термин «уберизация» относят к ис- пользованию компьютерных платформ, таких как мобильные приложения, для проведения сделок между клиентами и поставщиками услуг.

Следующей по частотности частью речи, которую образует французский язык от заимствований, являются глаголы (32 \%) и все они образуются по типу спряжения 1 группы, например:

- liker (гл.) - лайкнуть, выразить свое одобрение;

- troller (гл.) - троллить (размещать в Интернете: на форумах, в дискуссионных группах, и др., - провокационные сообщения с целью вызвать конфликты между субъектами и т. п.);

- code-barrer (гл.) - присваивать товару штрих код, штрихкодировать;

- oscariser (гл.) - награждать премией «Оскар».

Данная тенденция объясняется историей развития французского языка. Дело в том, что к 3 группе относятся неправильные глаголы, которые в процессе нормализации французского языка в XVII веке, ввиду частотности своего употребления, так и не были приведены к единой форме инфинитива и общему для всех глаголов группы способу спряжения. В свою очередь, глаголы 2 группы являются самой непродуктивной моделью в современном французском языке. Следовательно, дериваты от заимствований не могут образовываться по моделям этих групп глаголов. Также, при выборе модели словообразования от заимствований свою роль сыграл факт частотности глаголов 1 группы; соответственно, все новообразования образуются по более продуктивной модели, а именно 1 группы.

Реже всего от заимствованных слов образуются имена прилагательные (14\%), например:

- googlable - имеющий потенциальную возможность быть найденным с помощью поисковой системы Гугл;

- dystopique - антиутопический;

- oscarisable - имеющий потенциальную возможность быть награжденным кинопремией «Оскар»;

- trollesque - вызывающий негативную реакцию.

Как видно из приведенных выше примеров, чаще всего от заимствований дериваты образуются путем суффиксации - 56 \% от общего количества проанализированных примеров.

Другие способы образования новых слов по моделям французского языка представлены следующим образом: префиксация (16\%):

- autogoogliser - искать свои персональные данные в поисковой системе Гугл;

- surliker - выражать чрезмерное одобрение какому-либо материалу, опубликованному в Интернете; 


\section{словосложение (12\%):}

- datalogie - раздел информатики, изучающий проблемы анализа, обработки и представления данных в цифровой форме (наука о данных);

- twittosphère - существительное, которое объединяет все, что относится к пространству социальной сети Твиттер (как сообщество пользователей, так и публикуемые материалы, твиттосфера).

Самыми редкими способами словообразования от заимствований являются: конверсия (5\%), расширение значения слова за счет метафорического переноса (1 \%) и аббревиация (1\%).

Такое распределение продуктивности способов словообразования не является неожиданным и полностью соответствует тенденциям словообразования, существующим в современном французском языке.

Также были отмечены случаи совмещения способов словообразования (9 \%), например: microblogage (сущ., м. р.) - публикация небольших сообщений в микроблоге.

\section{ЛИТЕРАТУРА}

1. Ломизова Т.И. Лексикология французского языка: Учебное пособие для студентов заочного отделения. - Нижний Новгород: НГЛУ им. Н.А. Добролюбова, 2004. -142 c.

2. Маслов Ю.С. Категория предельности / непредельности глагольного действия в готском языке // Очерки по аспектологии. - Л.: 1984. - С. 209-224

3. Dictionnaire des mots nouveaux 2017 [Электронный ресурс] - Режим доступа: URL: https://www.lerobert.com/sites/default/files/common/docs/2017-CPmots-nouveaux.pdf

4. Dictionnaire des mots nouveaux 2018 [Электронный ресурс] - Режим доступа: URL: https://www.dictionnaire.exionnaire.com/dictionnaire-mots-nouveauxpetit-robert-2018-f4389.html

5. Dictionnaire des mots nouveaux 2019 [Электронный ресурс] - Режим доступа: URL: https://www.dictionnaire.exionnaire.com/dictionnaire-mots-nouveauxpetit-robert-2019-f4458.html

6. Dictionnaire des mots nouveaux 2020 [Электронный ресурс] - Режим доступа: URL: https://www.lerobert.com/mots-nouveaux-petit-robert.html

7. https://fr.wiktionary.org

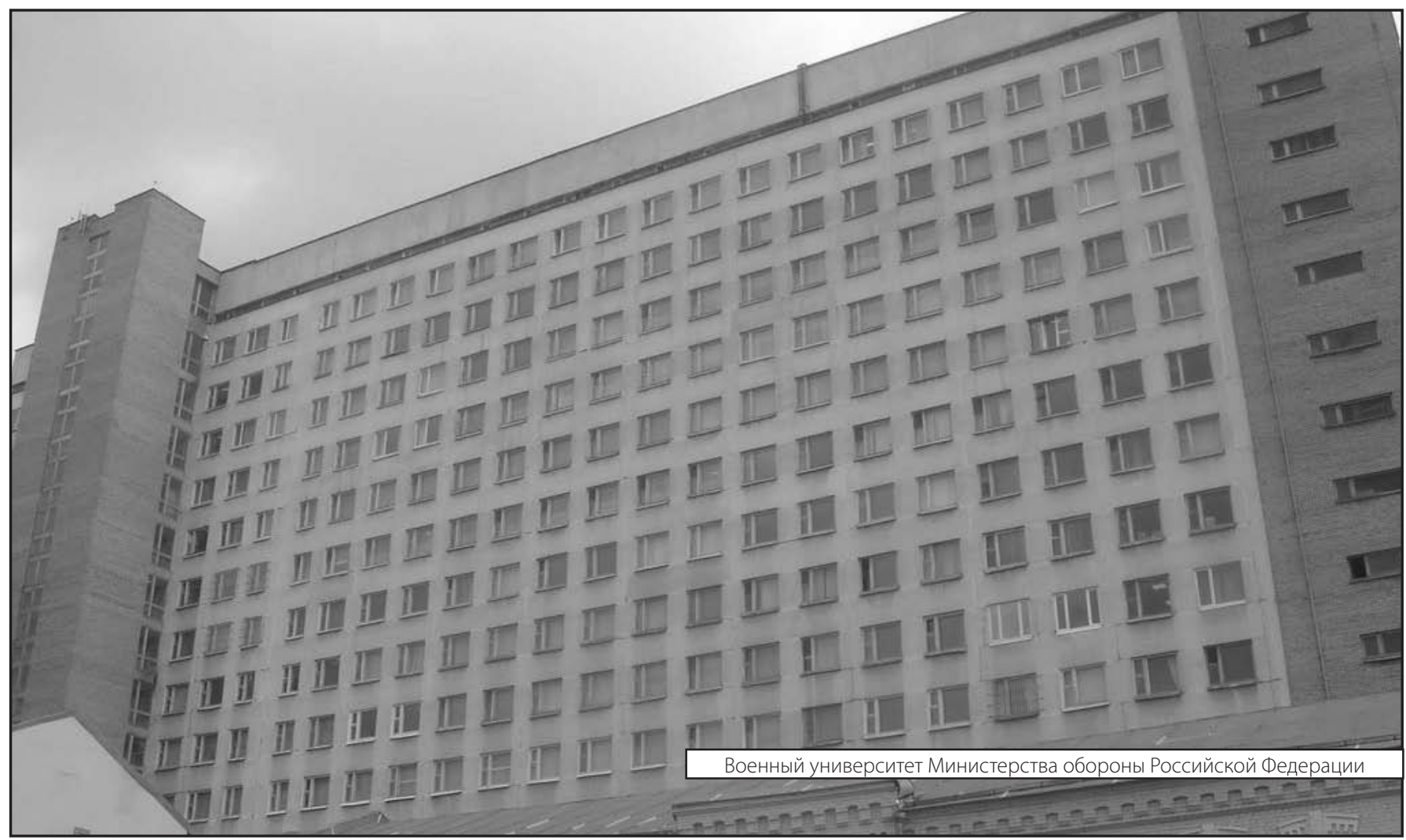

